\title{
Effects of Deleting Mitochondrial Antioxidant Genes on Life Span
}

\author{
ERCAN SELCUK UNLU AND AHMET KOC \\ Department of Biology, Izmir Institute of Technology, 35430 Urla, Izmir, Turkey
}

\begin{abstract}
Reactive oxygen species (ROS) damage biomolecules, accelerate aging, and shorten life span, whereas antioxidant enzymes mitigate these effects. Because mitochondria are a primary site of ROS generation and also a primary target of ROS attack, they have become a major focus area of aging studies. Here, we employed yeast genetics to identify mitochondrial antioxidant genes that are important for replicative life span. In our studies, it was found that among the known mitochondrial antioxidant genes (TTR1, CCD1, SOD1, GLO4, TRR2, TRX3, CCS1, SOD2, GRX5, PRX1), deletion of only three genes, SOD1 (Cu, $\mathrm{Zn}$ superoxide dismutase), SOD2 (Manganese-containing superoxide dismutase), and CCS1 (Copper chaperone), shortened the life span enormously. The life span decreased $40 \%$ for $\Delta \operatorname{sod} 1$ mutant, $72 \%$ for $\Delta \operatorname{sod} 2$ mutant, and $50 \%$ for $\Delta$ ccs 1 mutant. Deletion of the other genes had little or no effect on life span.
\end{abstract}

KEYWORDS: aging; antioxidant genes; mitochondria; ROS; CCS1

\section{INTRODUCTION}

Free radicals generated by aerobic metabolism cause oxidative damage to cell components, such as DNA, proteins, and lipids. Such damage results in altered structure and loss of biological function, which leads to aging and cell death. ${ }^{1}$ The mitochondrial respiratory chain on the inner mitochondrial membrane is a major intracellular source of reactive oxygen species (ROS) in eukaryotes. Since ROS are highly reactive and short-lived, mitochondria are continuously exposed to them and accumulate oxidative damage more rapidly than the rest of the cell. ${ }^{2}$ Various defense mechanisms operate in mitochondria to minimize the deleterious effects of oxidative stress and maintain the mitochondrial function. Some protective enzymes have direct role in scavenging free radicals, for example, superoxide dismutase is involved in the conversion of superoxide anion to $\mathrm{H}_{2} \mathrm{O}_{2}$, which is further detoxified by catalases or peroxidases. ${ }^{3}$ Enzymes that repair the products of oxidatively damaged

Address for correspondence: Ahmet Koc, Department of Biology, Izmir Institute of Technology, 35430 Urla, Izmir, Turkey. Voice: 90-232-750-7544; fax: 90-232-750-7509.

ahmetkoc@iyte.edu.tr

Ann. N.Y. Acad. Sci. 1100: 505-509 (2007). @ 2007 New York Academy of Sciences.

doi: 10.1196/annals.1395.055 
TABLE 1. List of mitochondrial antioxidant genes

\begin{tabular}{|c|c|c|}
\hline ORF (gene) & Gene product & Subcellular localization \\
\hline SOD2 & Mn superoxide dismutase & mitochondrial matrix \\
\hline$G R X 5$ & glutaredoxin & mitochondrial matrix \\
\hline$P R X 1$ & peroxiredoxin & mitochondrion \\
\hline$T R X 3$ & thioredoxin & mitochondrion \\
\hline$C C P 1$ & cytochrome c peroxidase & mitochondrial intermembrane space \\
\hline SOD1 & $\mathrm{Cu}, \mathrm{Zn}$ superoxide dismutase & cytosol, mitochondrial intermembrane space \\
\hline GLO4 & glyoxylase-II & mitochondrial matrix \\
\hline$T R R 2$ & thioredoxin reductase & mitochondrion \\
\hline$G R X 2$ & glutaredoxin & cytosol, mitochondrion \\
\hline CCS1 & copper chaperone & cytosol, mitochondrial inner membrane \\
\hline
\end{tabular}

components form the second line of antioxidant defense. ${ }^{4}$ If oxidative stress defense mechanisms are compromised or overwhelmed, disease states may develop. It has been proposed that mitochondrial oxidative damage contributes to neurodegenerative disorders, cancer, and the aging process in humans. ${ }^{5}$ Yeast (Saccharomyces cerevisiae) cell possesses a limited life span and is a good model organism to study the role of mitochondrial antioxidant genes in cellular aging. Aging in yeast is determined microscopically by counting the number of daughter cells produced by each cell. In this study, using yeast deletion mutants, the role of mitochondrial antioxidant genes on life span was investigated.

\section{MATERIALS AND METHODS}

\section{Yeast Strains and Media}

Wild-type (WT) and 10 different deletion mutants( $\Delta c c p 1, \Delta$ sodl, $\Delta$ glo4, $\Delta \operatorname{tr} 2, \Delta t r x 3, \Delta c c s 1, \Delta$ grx2, $\Delta \operatorname{sod} 2, \Delta$ grx $5, \Delta p r x 1)$ of $S$. cerevisiae were examined. Yeast strains were grown in rich YPD medium (1\% yeast extract, $2 \%$ peptone, and $2 \%$ glucose) for both growth and aging assays.

\section{Identification of Mitochondrial Antioxidant Genes}

Identification of mitochondrial antioxidant genes was carried out by using Mitochondrial Proteome Database (MitoP2). ${ }^{6}$

\section{Yeast Aging Assay}

Yeast strains were grown on fresh media for 2 days before analysis. For each strain, 20 daughter cells (starter mothers) were collected and lined up by a 
micromanipulator on agar plates. New buds (daughters) from these virgin cells were removed and discarded as they formed. This process continued until cells ceased dividing. Life span was determined as the total number of daughter cells that each mother cell generated.

\section{RESULTS AND DISCUSSION}

We first obtained a list of mitochondrial antioxidant proteins using MitoP2 program, which analyzes the mitochondrial targeting sequence in genes and

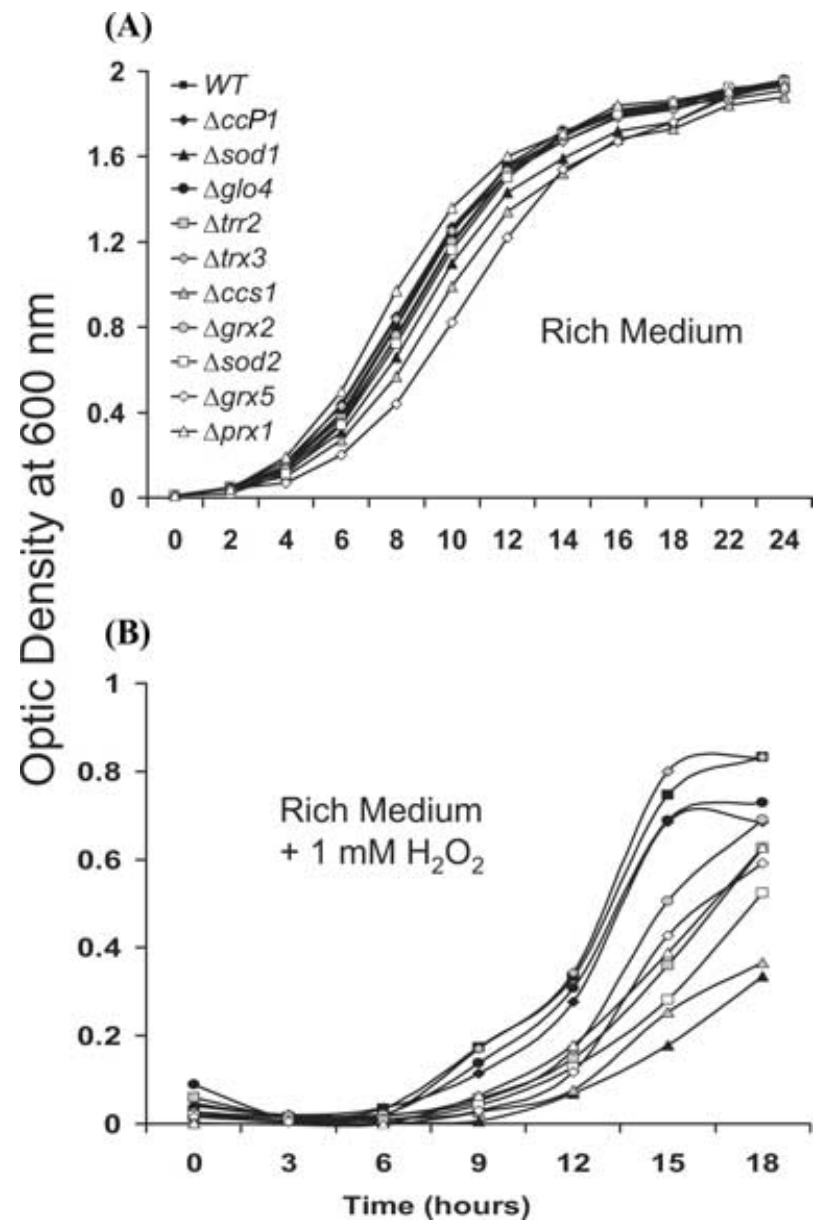

FIGURE 1. Overnight cultures were diluted to $0.05 \mathrm{OD}_{600}$ in liquid and shaked at $30^{\circ} \mathrm{C}$ for the indicated time. Growth rate was monitored by $\mathrm{OD}_{600}$ measurements. (A) Growth in rich (YPD) media. (B) Growth in rich media containing $1 \mathrm{mM} \mathrm{H}_{2} \mathrm{O}_{2}$. 


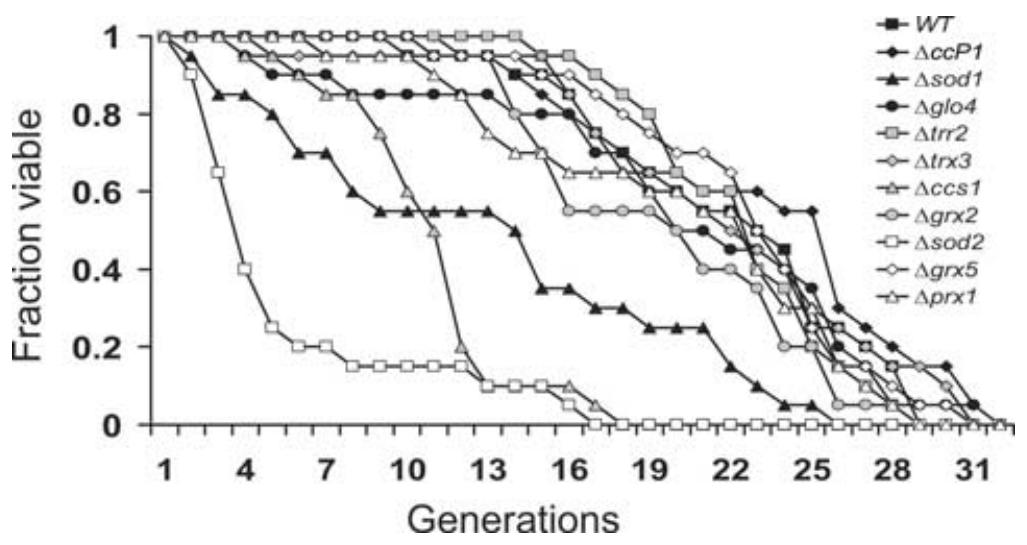

FIGURE 2. Replicative life span analyses of WT and mutant cells.

matches the results with published experimental data to predict localization of proteins with a high accuracy rate. ${ }^{6}$ As shown in TABLE 1, 10 different proteins were found to be antioxidant and residing in mitochondria. To investigate whether these genes are important in cell growth, deletion mutants were grown in rich medium and growth rate was followed by $\mathrm{OD}_{600}$ measurements. As shown in Figure 1 A, none of the mutants showed a significant growth defect under normal conditions, but mutants lacking GRX5, SOD2, $S O D 1, C C S 1, P R X 1, T R R 2$, and GRX2 genes grew slower when exposed to $1 \mathrm{mM}$ of $\mathrm{H}_{2} \mathrm{O}_{2}$ suggesting that these mutants are sensitive to oxidative stress (FIG. 1 B).

To see the effect of deleting these genes on life span, replicative aging profile of each mutant was determined. Deletion of SOD1, SOD2, and CCS1 genes caused a major drop in both average and maximum life spans (FIG. 2 and TABLE 2). The life span decrease was $40 \%$ for $\Delta \operatorname{sod} 1$ mutant, $72 \%$ for $\Delta \operatorname{sod} 2$ mutant, and $50 \%$ for $\triangle c c s 1$ mutant. Absence of GRX2, GLO4, and $P R X 1$ genes also shortened life span (10\%), but the extent of decrease was not as significant as deleting SOD1 and SOD2 or CCS1 genes. Surprisingly, deletion of the other mitochondrial antioxidant genes did not lead to a decrease in life span. Role of superoxide dismutases in aging was described earlier ${ }^{7,8}$ and our results are consistent with the previous findings.

TABLE 2. Maximum and average life spans of mutants

\begin{tabular}{lccccccccccc}
\hline & $W T$ & $\Delta c c P 1$ & $\Delta$ sod1 & $\Delta$ glo4 & $\Delta$ trr2 & $\Delta$ trx3 & $\Delta$ ccs1 & $\Delta$ grx2 & $\Delta$ sod2 & $\Delta$ grx5 & $\Delta$ prx 1 \\
\hline $\begin{array}{l}\text { Max life } \\
\quad 29\end{array}$ & 32 & 26 & 32 & 29 & 31 & 18 & 29 & 17 & 31 & 29 \\
$\begin{array}{c}\text { span } \\
\quad \begin{array}{l}\text { spane life } \\
\text { span }\end{array}\end{array}$ & 22 & 23 & 13 & 20 & 23 & 22 & 11 & 20 & 6 & 23 & 20 \\
\hline
\end{tabular}




\section{ACKNOWLEDGMENT}

This research was supported by the Turkish State Planning Organisation Grant 2003K120690 to A.K.

\section{REFERENCES}

1. Berlett, B.S. \& E.R. Stadtman. 1997. Protein oxidation in aging, disease, and oxidative stress. J. Biol. Chem. 272: 20313-20316.

2. Kowaltowski, A.J. \& A.E. VerCeSt . 1999. Mitochondrial damage induced by conditions of oxidative stress. Free Radic. Biol. Med. 26: 463-471.

3. Jensen, R.E., A.E. Hobbs, K.L. Cerveny \& H. Sesaki. 2000. Yeast mitochondrial dynamics: fusion, division, segregation, and shape. Microsc. Res. Tech. 51: 573583.

4. Moradas-Ferreira, P., V. Costa, P. Piper \& W. Mager. 1996. The molecular defences against reactive oxygen species in yeast. Mol. Microbiol. 19: 651-658.

5. Singh, K.K. 1998. Mitochondrial DNA Mutations in Aging, Disease and Cancer. Springer. New York, NY.

6. Andreoli, C., H. Prokisch, K. Hortnagel, et al. 2004. MitoP2, an integrated database on mitochondrial proteins in yeast and man. Nucleic Acids Res. 32: D459-D462.

7. Bonawitz, N.D., M.S. RodehefFer \& G.S. Shadel. 2006. Defective mitochondrial gene expression results in reactive oxygen species-mediated inhibition of respiration and reduction of yeast life span. Mol. Cell Biol. 26: 4818-4829.

8. Barker, M.G., L.J. Brimage \& K.A. Smart. 1999. Effect of Cu,Zn superoxide dismutase disruption mutation on replicative senescence in Saccharomyces cerevisiae. FEMS Microbiol. Lett. 177: 199-204. 